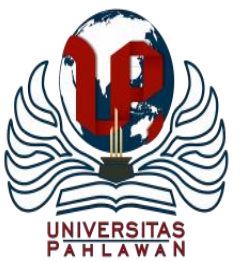

Jurnal Basicedu Volume 4 Nomor 3 Tahun 2020 Halm. 707 - 715

JURNAL BASICEDU

Research \& Learning in Elementary Education

https://jbasic.org/index.php/basicedu/index

\title{
Analisis Pelaksanaan Microteaching Mahasiswa PGSD Pada Mata Kuliah PSAP Sains Dan Teknologi
}

\author{
Year Rezeki Patricia Tantu ${ }^{1}$, Lizbeth Yulia Christi ${ }^{2}$ \\ Pendidikan Guru Sekolah Dasar, Fakultas Ilmu Pendidikan, Universitas Pelita Harapan \\ E-mail : year.rezeki@gmail.com ${ }^{1}$ lizbethyuliac@gmail.com ${ }^{2}$
}

\begin{abstract}
Abstrak
Kegiatan microteaching dapat mempersiapkan mahasiswa calon guru untuk menguasai kompetensi pedagogik. Penelitian ini bertujuan untuk menganalisa pelaksanaan kegiatan microteaching Sains dari mahasiswa calon guru SD di Universitas Pelita Harapan. Hasil analisa diharapkan dapat menjadi evaluasi bagi dosen yang mempersiapkan mahasiswa menjadi guru sains dan bagi mahasiswa calon guru untuk mengantisipasi kriteria-kriteria yang masih perlu ditingkatkan. Penelitian ini menggunakan metode deskriptif kuantitatif dengan instrumen rubrik penilaian microteaching dan lembar observasi dosen. Perhitungan kuantitatif dilakukan dengan menghitung persentase total perolehan skor dari setiap kriteria rubrik penilaian microteaching, kemudian dikonversi ke dalam data kualitatif melalui tabel persentase kriteria penilaian hasil belajar. Terdapat 7 kriteria yang dinilai berdasarkan rubrik penilaian microteaching, yaitu: pembukaan, metode mengajar, pemahaman konsep, media pembelajaran, manajemen kelas, keterampilan berbicara, dan penutup. Peneliti memperoleh hasil bahwa kegiatan microteaching yang dilaksanakan oleh mahasiswa Pendidikan Guru Sekolah Dasar angkatan 2016 sudah baik dengan persentase untuk kriteria pembukaan sebesar 62,82\% (cukup baik), metode mengajar sebesar 82,69\% (baik), pemahaman konsep sebesar 77,564\% (baik), media pembelajaran sebesar 77,85\% (baik), manajemen kelas 72,436\% (baik), keterampilan berbicara 82,051\% (baik), dan penutup 62,18\% (cukup baik). Berdasarkan persentase dari setiap kriteria penilaian microteaching, dapat diketahui bahwa kriteria yang masih perlu ditingkatkan lagi adalah kemampuan membuka pelajaran, manajemen kelas, dan menutup pelajaran.

Kata kunci: microteaching, pembelajaran mikro, kompetensi pedagogik
\end{abstract}

\begin{abstract}
Microteaching can prepare student teachers to master pedagogical competencies. This research aims to analyze the implementation of Science microteaching activities from prospective elementary teacher at Pelita Harapan University. The results of the analysis are expected to be an evaluation for lecturers who prepare students to become Science teachers for prospective teacher to anticipate criteria that still need to be improved. This research uses quantitative descriptive method by using microteaching assessment rubric and lecturer observation sheet. Quantitative calculation is done by calculating the percentage of the total score obtained from each criteria of microteaching assessment rubric, then converted into qualitative data through the percentage table assessment criteria of learning outcomes. There are 7 criterias that are assessed based on the microteaching assessment rubric, namely: opening, teaching method, concept understanding, learning media, classroom management, speaking skills, and closing. Researchers obtained results that the microteaching carried out by the 2016 Primary School Teacher Education students were good with the percentage for the opening criteria by $62.82 \%$ (good enough), teaching method by $82.69 \%$ (good), concept understanding by $77.564 \%$ (good), learning media by $77.85 \%$ (good), classroom management by $72.436 \%$ (good), speaking skills by $82.051 \%$ (good), and closing by $62.18 \%$ (good enough). Based on the percentage of each the microteaching assessment criteria, it can be seen that the criteria that still need to be improved are the ability to open the lesson, classroom management, and closing the lesson.
\end{abstract}

Keywords: microteaching, pedagogical competence

Copyright (c) 2020 Year Rezeki Patricia Tantu, Lizbeth Yulia Christi

$\triangle$ Corresponding author :

Address : Jalan Taman Ubud Permata Timur 1 No.25 Karawaci $\quad$ ISSN 2580-3735 (Media Cetak)

Email : year.tantu@uph.edu $\quad$ ISSN 2580-1147 (Media Online)

Phone : 087808446164

DOI :10.31004/basicedu.v4i3.424 
708 Analisis Pelaksanaan Microteaching Mahasiswa PGSD Pada Mata Kuliah PSAP Sains dan Teknologi Year Rezeki Patricia Tantu, Lizbeth Yulia Christi

DOI : 10.31004/basicedu.v4i3.424

\section{PENDAHULUAN}

Kesuksesan pembelajaran di kelas tidak terlepas dari peran guru yang menguasai kompetensi mengajar. Undang-Undang Nomor 14 Tahun 2005 tentang Guru dan Dosen, Pasal 8 menyatakan bahwa salah satu kompetensi yang harus dimiliki guru adalah kompetensi pedagogik. Lebih detil dijelaskan dalam Standar Nasional Pendidikan, pasal 28 ayat (3) butir a bahwa salah satu kemampuan dalam kompetensi pedagogik yang perlu dikuasai guru adalah kemampuan melaksanakan pembelajaran, yang meliputi kemampuan menerapkan keterampilan dasar mengajar, menerapkan berbagai jenis model strategi pembelajaran, menguasai kelas, dan mengukur tingkat ketercapaian kompetensi peserta didik. Berdasarkan standar nasional tersebut, para mahasiswa calon guru perlu dipersiapkan secara matang sehingga mereka mampu mengasah kompetensi pedagogik.

Salah satu mata kuliah yang mempersiapkan para mahasiswa calon guru SD di Universitas Pelita Harapan untuk mengasah kompetensi pedagogik mereka adalah Perencanaan, Strategi, Asesmen, Pembelajaran atau yang dikenal dengan sebutan PSAP. Kegiatan inti dalam mata kuliah ini adalah melakukan microteaching dalam kelas. Microteaching atau pembelajaran mikro dapat diartikan sebagai suatu pendekatan pembelajaran yang mempersiapkan dan meningkatkan kompetensi calon guru melalui program latihan pembelajaran yang disederhanakan (Sunaengsih \& Sunarya, 2018:5). Pembelajaran ini dikatakan sederhana karena dilakukan dalam ruang kelas tempat mahasiswa belajar dengan waktu yang cukup singkat. Melalui kegiatan microteaching ini, mahasiswa belajar mengasah keterampilan membuat perencanaan pembelajaraan (RPP) dengan tepat dan kreatif, kemudian mengeksekusi RPP yang dirancang melalui pengajaran di dalam kelas. Kegiatan microteaching ini juga menjadi sarana bagi mahasiswa calon guru untuk mengasah kemampuan menguasai konsep.

Salah satu mata pelajaran yang diajar oleh mahasiswa calon guru SD adalah Sains (Ilmu Pengetahuan Alam). Pembelajaran Sains bagi anak Sekolah Dasar memiliki keunikan tersendiri karena mengandung beberapa konsep yang abstrak serta memiliki natur yang berorientasi pada proses dan juga produk. Penting bagi mahasiswa calon guru SD untuk mengetahui keunikan dari Sains sehingga mampu memilih strategi yang tepat dalam mengajar. Melalui kegiatan microteaching, mahasiswa calon guru SD ditantang untuk menciptakan pembelajaran bermakna yang dapat membawa para murid bertanggung jawab memelihara alam ciptaan Tuhan melalui keterampilan berproses.

Kegiatan microteaching dapat menjadi sarana belajar yang baik bagi mahasiswa sebelum mereka terjun dalam praktik lapangan serta menjadi guru nanti. Dalam pelaksanaan microteaching, Ardi (2014) memperoleh hasil mengenai persentase dari aspek keterampilan microteaching, yaitu menutup dan membuka pelajaran $(84,94 \%)$ dengan kategori baik, menjelaskan materi $(94,75 \%)$ dengan kategori sangat baik, dan mengelola kelas $(72,41 \%)$ dengan kategori baik. 
709 Analisis Pelaksanaan Microteaching Mahasiswa PGSD Pada Mata Kuliah PSAP Sains dan Teknologi Year Rezeki Patricia Tantu, Lizbeth Yulia Christi

DOI :10.31004/basicedu.v4i3.424

Penelitian yang dilakukan oleh Kansil \& Fredy (2017) menunjukkan bahwa dalam pelaksanaan kegiatan microteaching untuk aspek pembuka dan penutup berada pada kategori baik dengan persentase penilaian sebesar $84,41 \%$, keterampilan menjelaskan berada pada kategori baik $(82,40 \%)$, dan keterampilan mengelola kelas berada pada kategori baik $(81,90 \%)$.

Adapun persentase komponen penilaian penampilan microteaching pada penelitian yang lain diperoleh hasil sebagai berikut: keterampilan membuka pelajaran $(73,2 \%)$ dengan kategori baik, keterampilan menggunakan media pembelajaran $(78,5 \%)$ dengan kategori baik, keterampilan memilih metode (65\%) dengan kategori cukup baik, keterampilan menjelaskan (75\%) dengan kategori baik, keterampilan mengelola kelas $(60,2 \%)$ dengan kategori cukup baik, dan keterampilan menutup pelajaran (74\%) dengan kategori baik (Agustina, 2019). Beberapa hasil penelitian analisa kegiatan microteaching di atas memberikan hasil yang beragam dengan minimal kategori cukup baik.

Oleh karena itu, tujuan penulisan makalah ini adalah untuk menganalisa pelaksanaan microteaching Sains mahasiswa calon guru SD di Universitas Pelita Harapan. Hasil analisa dapat menjadi evaluasi bagi dosen yang mempersiapkan mahasiswa menjadi guru Sains dan menjadi evaluasi bagi para mahasiswa calon guru untuk mengantisipasi kriteria-kriteria yang masih perlu ditingkatkan. Bagi para pembaca lain, paper ini juga dapat memberi gambaran bahwa kegiatan microteaching sangat bermanfaat dalam melatih kompetensi pedagogik mahasiswa calon guru SD.

\section{METODE}

Penelitian ini menggunakan metode deskriptif kuantitatif. Perhitungan kuantitatif yang dipakai merupakan perhitungan persentase sederhana setiap kriteria yang dinilai dalam kegiatan microteaching. Lokasi penelitian di Fakultas Ilmu Pendidikan, Universitas Pelita Harapan. Subjek penelitian adalah mahasiswa Pendidikan Guru Sekolah Dasar angkatan 2016 berjumlah 39 orang. Sampel diambil dengan menggunakan teknik pengambilan data secara purposive. Penelitian dilaksanakan pada bulan Februari sampai bulan April 2019.

Adapun instrumen yang dipakai dalam proses menganalisis pelaksanaan microteaching Sains bagi mahasiswa PGSD ini adalah rubrik penilaian microteaching dan lembar observasi dosen. Rubrik penilaian microteaching memiliki 7 kriteria, yaitu: Pembukaan, Metode Mengajar, Pemahaman Konsep, Media Pembelajaran, Manajemen Kelas, Keterampilan Berbicara, dan Penutup. Rubrik digunakan untuk menilai tinggi atau rendahnya skor kinerja dari setiap kriteria yang telah ditentukan (Djulia et al., 2020). Setiap kriteria pada rubrik microteaching memiliki skala penskoran yang terdiri dari: 4 (Sangat Baik), 3 (Baik), 2 (Cukup), dan 1 (Kurang).

Perhitungan kuantitatif menggunakan hasil dari rubrik penilaian microteaching dengan menghitung total perolehan skor untuk masingmasing kriteria, kemudian diubah dalam bentuk persentase. Menurut Yuanita (2019) perubahan skor menjadi persentase menggunakan rumus sebagai berikut: 
710 Analisis Pelaksanaan Microteaching Mahasiswa PGSD Pada Mata Kuliah PSAP Sains dan Teknologi Year Rezeki Patricia Tantu, Lizbeth Yulia Christi DOI : 10.31004/basicedu.v4i3.424

$$
\begin{array}{ll}
\multicolumn{1}{c}{\mathbf{N P}=\mathbf{R} / \mathbf{S M} \mathbf{X} \mathbf{1 0 0 \%}} \\
\mathrm{NP}: \text { Nilai Persentase } \\
\mathrm{R} \quad \text { : Skor yang diperoleh } \\
\mathrm{SM}: \text { Skor Maksimum }
\end{array}
$$

Sumber: Yuanita (2019)

Hasil persentase kemudian dikonversi ke dalam data kualitatif dengan menggunakan kriteria penilaian hasil belajar yang diadaptasi dari kategori persentase pada penelitian pada tabel berikut (Kolai et al., 2016):

Tabel 1. Kriteria Penilaian Hasil Belajar

\begin{tabular}{|c|c|}
\hline Persentase (\%) & Predikat \\
\hline $86-100$ & Sangat Baik \\
\hline $76-85,99$ & Baik \\
\hline $60-75,99$ & Cukup \\
\hline $55-59,99$ & Kurang \\
\hline$\leq 54,99$ & Sangat Kurang \\
\hline
\end{tabular}

Sumber: (Kolai et al., 2016)

Hasil tersebut kemudian dianalisa dan dijelaskan secara deskriptif dengan menggunakan catatan dari lembar observasi dosen.

\section{HASIL DAN PEMBAHASAN}

Berdasarkan gambar 1, dapat diketahui bahwa kriteria dengan persentasi paling tinggi adalah strategi/metode mengajar sebesar $82,69 \%$ (baik). Hal ini menunjukkan bahwa mahasiswa calon guru PGSD sudah baik dalam memilih strategi/metode pembelajaran yang dapat mengarahkan siswa untuk aktif belajar. Kriteria dengan persentase yang tergolong tinggi kedua adalah keterampilan berbicara sebesar $82,051 \%$ (baik), sehingga mahasiswa juga sudah menampilkan percaya diri yang baik saat mengajar. Kriteria media pembelajaran $(77,85 \%)$, pemahaman konsep $(77,564 \%)$, dan manajemen kelas $(72,436 \%)$ termasuk dalam kategori baik. Sedangkan, untuk kriteria pembuka $(62,82 \%)$ dan kriteria penutup $(62,18 \%)$ termasuk dalam kategori cukup baik.

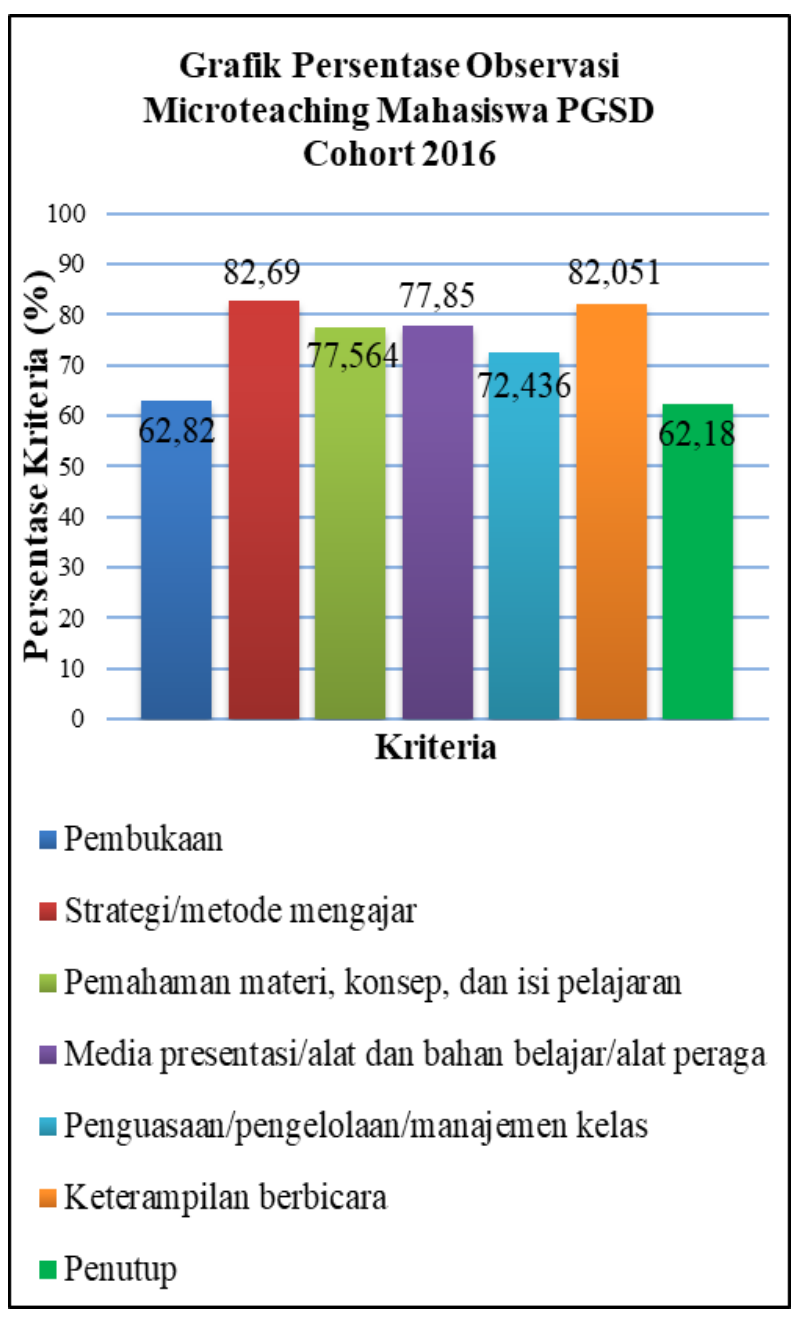

Gambar 1. Grafik Persentase Penilaian Microteaching

\section{Kemampuan Membuka Pelajaran}

Berdasarkan data yang diperoleh, mahasiswa calon guru PGSD sudah cukup baik dalam membuka pelajaran. Beberapa indikator 
711 Analisis Pelaksanaan Microteaching Mahasiswa PGSD Pada Mata Kuliah PSAP Sains dan Teknologi Year Rezeki Patricia Tantu, Lizbeth Yulia Christi

DOI :10.31004/basicedu.v4i3.424

yang dinilai dalam bagian pembukaan adalah kemampuan menarik perhatian siswa sebelum mengajar, kemampuan menyampaikan tujuan pembelajaran afektif, kognitif, dan psikomotor, kemampuan untuk memotivasi siswa, dan mereview pembelajaran serta menghubungkan dengan pembelajaran yang dibawakan. Sebagian besar mahasiswa sudah bisa menarik perhatian siswa sebelum mengajar. Namun, sebagian mahasiswa belum mampu memberikan fokus melalui tujuan pembelajaran secara utuh kepada siswa, kurang memberikan motivasi pada awal pembelajaraan, dan kurang dalam memberikan review terkait dengan pembelajaran yang dilakukan. Melalui catatan observasi, terlihat bahwa mahasiswa calon guru memberikan review atau pertanyaan kepada siswa, tetapi review kurang berhubungan dengan materi pembelajaran yang diajarkan dan review yang diberikan kurang mendalam. Fakta lain yang ditemukan pada saat observasi adalah mahasiswa calon guru belum menyampaikan tujuan pembelajaran secara utuh, baik dari ranah kognitif, psikomotor, maupun afektif.

Penting bagi setiap guru untuk dapat membuka pelajaran dengan sangat baik karena pada bagian ini, siswa dapat mengetahuai tujuan pembelajaran yang akan dicapai. Sanjaya (2015) mengatakan bahwa tujuan pembelajaran adalah kompetensi atau keterampilan yang diharapkan dapat dimiliki oleh siswa setelah mereka melakukan proses pembelajaran. Sebelum memasuki kegiatan inti, siswa perlu mengetahui kompetensi atau keterampilan yang perlu dikembangkan melalui pembelajaran yang dilakukan. Hal ini pun dapat membantu siswa untuk bisa melakukan evaluasi diri setelah pembelajaran berakhir. Prastowo (2017) menambahkan bahwa rumusan tujuan pembelajaran menjadi akuntabilitas kinerja guru dan mendorong komitmen guru untuk menciptakan pengalaman belajar yang menarik, efektif, dan efisien dalam pencapaian tujuan pembelajaran. Oleh karena itu, tujuan pembelajaran perlu disampaikan kepada setiap siswa diawal pembelajaran sehingga pembelajaran dapat lebih terarah dan efektif.

Selain itu, ketika guru dapat membuka pelajaran dengan baik, siswa dapat termotivasi untuk belajar pada tahap berikutnya. Ada banyak aktivitas yang dapat dipakai oleh guru untuk dapat membuat siswa-siswa memiliki motivasi untuk belajar hingga akhir.

\section{Strategi/Metode Mengajar}

Mahasiswa calon guru PGSD sudah baik dalam memilih metode pembelajaran untuk mata pelajaran Sains. Sutikno (2009) mengatakan bahwa metode pembelajaran adalah cara-cara menyajikan materi pelajaran yang dilakukan oleh pendidik agar terjadi proses pembelajaran pada diri siswa dalam upaya untuk mencapai tujuan. Berdasarkan data yang diperoleh, sebagian besar mahasiswa calon guru sudah melibatkan seluruh siswa dengan aktif melalui metode pembelajaran yang bersifat dua arah. Beberapa mahasiswa menggunakan pembelajaran inkuiri yang dapat membuat siswa aktif dalam menjawab pertanyaanpertanyaan. Sebagian besar mahasiswa juga sudah terlihat mahir dalam mengakomodir keragaman 
712 Analisis Pelaksanaan Microteaching Mahasiswa PGSD Pada Mata Kuliah PSAP Sains dan Teknologi Year Rezeki Patricia Tantu, Lizbeth Yulia Christi

DOI :10.31004/basicedu.v4i3.424

learning style siswa, baik secara audio dan visual melalui media pembelajaran, serta kinestetik melalui aktivitas langsung seperti eksperimen sederhana dan role play. Sebagian besar mahasiswa juga sudah mampu mengembangkan sikap kerja sama dan saling menghargai di antara siswa melalui tugas kelompok yang diberikan. Sebagian kecil mahasiswa perlu untuk melakukan eksplorasi strategi mengajar sehingga mampu membawakan pembelajaran yang efektif kepada siswa.

Indikator yang masih perlu ditingkatkan dalam pemilihan strategi mengajar adalah dapat mendukung siswa memahami konsep. Keefektifan metode pembelajaran tidak terlepas dari peran guru yang membawakan metode tersebut di dalam kelas. Setiap metode memiliki keunikan tersendiri dan kelebihannya, tetapi keberhasilan metode tersebut dibawakan dalam kelas adalah tergantung dari cara guru menyajikan metode tersebut. Melalui metode yang dipakai, guru perlu hadir dalam mendukung siswa dapat memahami konsep yang dipelajari. Bukan hanya sekedar fakta Sains yang diajarkan, tetapi siswa harus bisa menangkap konsep dari pembelajaran Sains.

\section{Pemahaman Konsep Sains}

Mahasiswa calon guru PGSD sudah mampu memahami konsep Sains dengan baik. Guru perlu menguasai konsep pelajaran dengan baik sehingga dapat mentransfernya kepada para siswa. Pemahaman konsep perlu ditanamkan kepada peserta didik sejak dini yaitu sejak anak tersebut masih duduk di bangku sekolah dasar (Herawati et al., 2013). Sebagian besar mahasiswa menguasai konsep materi karena mereka mampu menjawab pertanyaan-pertanyaan yang dilontarkan oleh siswa ketika mengajar. Mereka mengajar dengan sistematis dan terstruktur. Hal ini sangat penting untuk anak sekolah dasar karena karakteristik anak usia sekolah dasar adalah memiliki rasa ingin tahu yang sangat tinggi. Mereka pun berada dalam tahap pengenalan sehingga penting untuk dapat membawakan materi secara sistematis dan terstruktur.

Indikator yang masih perlu ditingkatkan adalah kemampuan menekankan konsep-konsep penting atau konsep kunci dari pembelajaran yang signifikan, relevan, dan menantang bagi para siswa.

\section{Media Pembelajaran}

Salah satu hal sangat mendukung proses pembelajaran adalah tersedianya media pembelajaran yang menarik dan efektif untuk anak-anak SD. Keefektifan media pembelajaran dinilai dari kesesuaian media dengan tujuan pembelajaran, berfungsi membantu siswa mengerti tentang konsep yang diajarkan, sesuai dengan karakteristik siswa, serta menarik minat siswa. Mahasiswa calon guru PGSD sudah baik dalam menyediakan media pembelajaran yang efektif. Media pembelajaran yang efektif adalah media pembelajaran yang dapat membuat siswa mengalami langsung pembelajaran yang ada. Ketika belajar tentang Sains, para siswa sebaiknya dibawa mendekat kepada alam. Keterbatasan untuk mendekat dengan alam, dapat dijembatani dengan pembuatan alat peraga yang dibuat menyerupai alam. Guru Sains harus dapat 
713 Analisis Pelaksanaan Microteaching Mahasiswa PGSD Pada Mata Kuliah PSAP Sains dan Teknologi Year Rezeki Patricia Tantu, Lizbeth Yulia Christi

DOI :10.31004/basicedu.v4i3.424

menyediakan media pembelajaran bagi anak SD agar membantu mereka melihat secara nyata, mendorong rasa ingin tahu, dan memahami konsep lebih baik. Hal tersebut juga didukung oleh hasil penelitian yang menujukkan bahwa dengan adanya media pembelajaran, siswa sangat tertarik untuk belajar dan lebih termotivasi karena memperoleh gambaran jelas dari konsep yang dipelajari (Rejeki et al., 2020).

\section{Manajemen Kelas}

Kemampuan manajemen kelas adalah kemampuan guru untuk menciptakan situasi belajar kondusif (Helsa \& Hendriati, 2017). Pemilihan strategi metode mengajar yang baik, penguasaan konsep, penyediaan media pembelajaran tidak akan menjadi efektif jika situasi belajar tidak terkontrol. Manajemen kelas adalah salah satu kriteria yang sangat mendukung tercapainya pembelajaran yagn efektif. Hasil penelitian yang dilakukan oleh Nurmaya (2019) juga menyatakan hal yang serupa bahwa pembelajaran yang efektif mempersyaratkan keterampilan manajerial dari seorang guru, yaitu kemampuan untuk menciptakan kelas yang kondusif untuk belajar. Beberapa indikator yang dinilai melalui kriteria ini adalah pengaturan waktu, pengaturan lingkungan kelas yang efektif, dan pengelolaaan perilaku siswa secara konsisten. Mahasiswa calon guru SD sudah baik dalam melakukan manajemen kelas. Ada banyak strategi yang membantu para mahasiswa dalam mengendalikan situasi kelas, seperti pemberian rules and procedures di awal pembelajaran, pemberian reinforcement untuk meningkatkan motivasi belajar, maupun pemberian punishment untuk mendisiplinkan siswa. Para mahasiswa calon guru SD memiliki ide-ide yang kreatif dalam mengatur kelas yang diajar.

\section{Keterampilan Berbicara}

Keterampilan berbicara merupakan suatu proses untuk mengekspresikan, menyatakan, serta menyampaikan ide, pikiran, gagasan, atau isi hati kepada orang lain dengan menggunakan bahasa lisan yang dapat dipahami oleh orang lain (Nurhasnah, 2018). Kesuksesan guru dalam mengajar sangat didukung oleh keterampilan berbicara yang baik. Berdasarkan data yang diperoleh, mahasiswa calon guru SD sudah memiliki keterampilan berbicara yang baik. Mereka mampu mengajar dengan volume suara sesuai dengan kondisi kelas, menggunakan tempo bicara yang tepat, menggunakan tata bahasa yang baik dan jelas, serta memiliki kontak mata langsung dan bahasa tubuh yang sesuai ketika mengajar.

\section{Kemampuan Menutup Pelajaran}

Pada bagian penutup, mahasiswa diharapkan mampu membimbing siswa untuk menyimpulkan pembelajaran, mengecek kembali pemahaman siswa, mempertegas pengerjaan tugas mandiri, dan memberikan nasehat atau motivasi kepada siswa terkait pembelajaran yang sudah dilakukan. Terlihat bahwa mahasiswa sudah cukup baik dalam menutup pembelajaran. Berdasarkan catatan observasi yang ada, sebagian mahasiswa tidak mampu menutup pelajaran dengan baik karena waktu pembelajaran sudah berakhir. Dalam 
714 Analisis Pelaksanaan Microteaching Mahasiswa PGSD Pada Mata Kuliah PSAP Sains dan Teknologi Year Rezeki Patricia Tantu, Lizbeth Yulia Christi

DOI :10.31004/basicedu.v4i3.424

microteaching ini, mahasiswa diberi waktu selama

30 menit untuk mengajar. Sebagian besar mahasiswa tidak memberikan tugas mandiri kepada siswa dan tidak memberikan nasehat atau motivasi terkait pembelajaran yang dibawakan. Kebanyakan mahasiswa hanya memberi kesimpulan dan langsung mengakhiri pembelajaran yang dibawakan. Sekalipun ada di akhir, bagian penutup penting untuk diperhatikan karena melalui bagian inilah siswa merangkum semua pembelajaran yang dilakukan. Pada bagian penutup, guru juga perlu melakukan evaluasi melalui cek pemahaman kepada siswa untuk melihat ketercapaian tujuan pembelajaran yang diberikan pada bagian pembukaan.

Berdasarkan ketujuh kriteria yang dinilai, mahasiswa calon guru SD sudah baik dalam melakukan kegiatan microteaching. Terdapat kriteria yang masih perlu diasah oleh para mahasiswa adalah kemampuan membuka pelajaran dengan baik, kemampuan memanajemen kelas, dan kemampuan menutup pembelajaran agar bisa menjadi lebih baik. Seluruh kriteria dalam pelaksanaan microteaching saling berkaitan satu dengan yang lain. Tidak ada kriteria yang lebih tinggi atau lebih unggul dari yang lain. Setiap kriteria dibutuhkan untuk tercapainya pembelajaran yang efektif. Jika dilihat secara individu berdasarkan catatan observasi, mahasiswa calon guru masih perlu mengembangkan kompetensi pada setiap kriteria microteaching yang dijelaskan.

\section{UCAPAN TERIMA KASIH}

Terima kasih kepada LPPM Universitas Pelita Harapan yang mendanai publikasi jurnal ini.

\section{SIMPULAN}

Berdasarkan penelitian yang telah dilakukan, dapat peneliti simpulkan bahwa kegiatan microteaching mahasiswa Pendidikan Guru Sekolah Dasar angkatan 2016 sudah baik, namun terdapat tiga kriteria yang masih perlu ditingkatkan lagi yaitu dalam hal kemampuan membuka pelajaran, manajemen kelas, dan menutup pelajaran.

\section{DAFTAR PUSTAKA}

Agustina, L. (2019). Analisis Penampilan Praktik Microteaching Mahasiswa Program Studi Pendidikan Biologi Tahun Pelajaran 2017/2018. Seminar Nasional Pendidikan Sains 2019, 59-63.

Ardi, M. (2014). Pelaksanaan Pembelajaran Bagi Mahasiswa Program Studi PPKn STKIPPGRI Pontianak. Jurnal Edukasi, 1(88), 7584.

Djulia, E., Hasrudin, Arwita, W., Simatupang, Z., Brata, W. W. W., Sipayung, M., Aryeni, Amrizal, Simatupang, H., Rezeqi, S., Pratiwi, N., \& Purnama, D. (2020). Evaluasi Pembelajaran Biologi. Yayasan Kita Menulis.

https://books.google.co.id/books?id=GrjQDw AAQB AJ\&printsec $=$ frontcover\&dq=evaluasi + pembelajaran + biologi $\& \mathrm{hl}=\mathrm{id} \& \mathrm{sa}=\mathrm{X} \& \mathrm{ved}=$ 0ahUKEwi_kJHo8NvpAhWHbisKHW1EAt YQ6AEIKDAA\# $\mathrm{v}=$ onepage $\& \mathrm{q}=$ evaluasi pembelajaran biologi\& $\mathrm{f}=$ false

Helsa, H., \& Hendriati, A. (2017). KEMAMPUAN 
715 Analisis Pelaksanaan Microteaching Mahasiswa PGSD Pada Mata Kuliah PSAP Sains dan Teknologi Year Rezeki Patricia Tantu, Lizbeth Yulia Christi

DOI : $10.31004 /$ basicedu.v4i3.424

MANAJEMEN KELAS GURU: PENELITIAN TINDAKAN DI SEKOLAH DASAR DENGAN SES RENDAH. Jurnal Psikologi, $\quad$ 16(2), 89. https://doi.org/10.14710/jp.16.2.89-104

Herawati, O. D. P., Siroj, R., \& Basir, D. (2013). Pengaruh Pembelajaran Problem Posing Terhadap Kemampuan Pemahaman Konsep Matematika Siswa Kelas Xi Ipa Sma Negeri 6 Palembang. Jurnal Pendidikan Matematika, 4(1). https://doi.org/10.22342/jpm.4.1.312.

Kansil, Y. E. Y., \& Fredy. (2017). Analisis Keterampilan Dasar Mengajar Mahasiswa PGSD pada Mata Kuliah Microteaching. Prosiding Seminar Nasional Himpunan Dosen PGSD Indonesia Wilayah IV, 49-59.

Kolai, K., Zainudin, \& Suryani. (2016). Peningkatan aktivitas belajar peserta didik melalui penerapan metode eksperimen pada pembelajaran ipa kelas iv. Program Studi Pendidikan Guru Sekolah Dasar FKIP Untan, 1, 1-13.

Nurhasnah, N. (2018). UPAYA MENINGKATKAN KETERAMPILAN BERBICARA MELALUI METODE PEMBELAJARAN LIHAT UCAP DI KELAS I SDN 005 KOTO SENTAJO KECAMATAN SENTAJO RAYA. JURNAL PAJAR (Pendidikan dan Pengajaran). https://doi.org/10.33578/pjr.v2i3.5528

Nurmaya, A. L. (2019). Peranan Manajemen Kelas dalam Meningkatkan Efektivitas Pembelajaran di Sekolah Dasar Kota Baubau. Jurnal basicedu, 3(2), 736-745.

Prastowo, A. (2017). Menyusun Rencana Pelaksanaan Pembelajaran (RPP) Tematik Terpadu. In Kencana.

Rejeki, Adnan, M. F., \& Siregar, P. S. (2020).
Pemanfaatan Media Pembelajaran pada Pembelajaran Tematik di Sekolah Dasar. Jurnal basicedu, 4(2), 337-343.

Sanjaya, W. (2015). Perencanaan dan Desain Sistem Pembelajaran. In Kencana,Prenadamedia Group.

Sunaengsih, C., \& Sunarya, D. T. (2018). Pembelajaran Mikro. UPI Sumedang Press.

Sutikno, M. S. (2009). Belajar dan Pembelajaran. Prospect.

Yuanita, Y. (2019). Tingkat Keterampilan Dasar Mengajar Calon Guru Sekolah Dasar Pada Perkuliahan Mikroteaching [Level of Basic Skills for Teaching Prospective Primary School Teachers at Mikroteaching Lectures]. PEDAGOGIA: Jurnal Pendidikan, 8(1), 69. https://doi.org/10.21070/pedagogia.v8i1.1952 